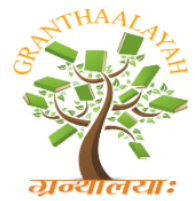

\author{
INTERNATIONAL JOURNAL OF RESEARCH - \\ GRANTHAALAYAH \\ A knowledge Repository
}

Science

\title{
MODIFICATION AND CHARACTERIZATION OF CEIBA PENTANDRA (L.) GAERTN. (KAPOK) FIBER: PHYSICAL PROPERTIES
}

\author{
Eduart Wolok ${ }^{1}$, Idham Halid Lahay ${ }^{1}$, Buyung R. Machmoed ${ }^{1}$, Fahriadi Pakaya *1 \\ ${ }^{1}$ Department of Industrial Engineering, Faculty of Engineering, Gorontalo State University, Kota \\ Gorontalo 96128, Indonesia
}

\begin{abstract}
Kapok fiber is a natural material that has unique properties, can be renewed with a large lumen, it has hydrophobic properties, as an absorbent in oil, heavy metals, and sound. To increase the absorption capacity of heavy metals, physical properties, and chemical resistance, modifications were made to change the fiber properties from hydrophobic to hydrophilic. One way is through the process of soaking the kapok fibers in a solvent to remove non-cellulose compounds. In this study, to improve the properties of kapok fiber, soaking has been done with various solutions, there are $\mathrm{HCl}, \mathrm{NaOH}, \mathrm{NaClO}, \mathrm{NaClO}-\mathrm{NaOH}-\mathrm{NaClO}$, and $\mathrm{NaClO} 2-\mathrm{NaOH}-\mathrm{NaClO} 2$ solution. Immersion of kapok fibers in $\mathrm{NaClO} 2-\mathrm{NaOH}-\mathrm{NaClO} 2$ solution can increase cellulose content up to $93.69 \%$ with porosity content of $4.75 \%$. $\mathrm{NaClO} 2-\mathrm{NaOH}-\mathrm{NaClO} 2$-treated can absorb water up to $211.27 \%$, the second highest after treatment with the $\mathrm{NaClO}-\mathrm{NaOH}-\mathrm{NaClO}$-treated solution of $285.29 \%$. Immersion in $\mathrm{NaClO}-\mathrm{NaOH}-\mathrm{NaClO}$ and $\mathrm{NaClO} 2-\mathrm{NaOH}-\mathrm{NaClO} 2$ solvents also causes damage to the kapok fiber protective layer which indicates the loss of lignin, so that a significant change of the hydrophobic fiber becomes hydrophilic as seen in the SEM results.
\end{abstract}

Keywords: Kapok Fiber; Alkalization; Oxidation; Hydrophilic; Chemical Resistance.

Cite This Article: Eduart Wolok, Idham Halid Lahay, Buyung R. Machmoed, and Fahriadi Pakaya. (2019). "MODIFICATION AND CHARACTERIZATION OF CEIBA PENTANDRA (L.) GAERTN. (KAPOK) FIBER: PHYSICAL PROPERTIES.” International Journal of Research Granthaalayah, 7(7), 381-390. https://doi.org/10.29121/granthaalayah.v7.i7.2019.791.

\section{Introduction}

The kapok tree (Ceiba Pentandra L.) is one type of tropical tree that grows in Indonesia, one of which is in the province of Gorontalo. So far, the utilization of kapok fiber for Gorontalo is still low. The use of kapok fiber is only based on conventional utilization, for example as raw material for bolster pillows. However, because there are many foam cushions available, this has caused a decline in the interest of kapok-based bolster pillow makers. Kapok fiber is a natural material that can be renewed with a large lumen and has hydrophobic properties and can be used as a sorbent in oil ${ }^{[1]}$. Kapok fiber is a natural hollow fiber with a thin layer and a large cavity that is used as an adsorbent for heavy metal ions ${ }^{[2]}$. Kapok fiber has unique properties and with these properties 
allows many new uses that can be developed. Based on previous research, kapok fiber can be used as an adsorbent material for heavy metals, oil, and sound.

Wahi ${ }^{[3]}$ said that the behavior of increasing waste oil pollution increased with the expansion of oil exploration and production activities. Wahi added that the use of natural fiber sorbents as adsorbents to remove oil from waste is the right step considering that besides being able to remove oil, it is also environmentally friendly, easy availability, feasibility, and effectiveness. Alkali treatment is able to change the hydrophobic nature of kapok fiber into new fibers which are hydrophilic and have the potential as natural sorbent oil because of their high adsorption rate, stable structure and high reusability ${ }^{[4]}$. Because it has hydrophobic-oleophilic characteristics, a homogeneous hollow tube shape, and low density, kapok fibers are often used as filler fibers in pillows and oil sorbents. Hori ${ }^{[5]}$ in their research stated that kapok fiber can be used as an excellent oil adsorbent.

The use of kapok as an adsorbent material because this material is a biodegradable material. Wang

[1] mentioned in his research that kapok fiber soaked in $\mathrm{NaClO}_{2}$ can increase the absorbance properties of the oil. Soaking kapok fiber in $\mathrm{NaClO}_{2}$ solution can change the nature of kapok fiber from hydrophobic to hydrophilic where almost all phenolic compounds are released from the fiber. The addition of $\mathrm{NaClO}_{2}$ has the positive effect on the efficiency of oil content absorbance. Duan ${ }^{[2]}$ in they research stated that the modification of fiber fibers using diethylenetriamine pentaacetic acid (DTPA) can be used as adsorbents in $\mathrm{Pb}^{2+}$ and $\mathrm{Cd}^{2+}$ ions. Based on the results of his research stated that kapok-DTPA fiber has better adsorbent capacity compared to the results of studies that have been reported specifically using natural fibers. Adsorption capacity decreases with decreasing $\mathrm{pH}$. Chemical modification of kapok fiber application can be used as an alternative if we want to remove $\mathrm{Pb}^{2+}$ metal ion content in industrial waste ${ }^{[6]}$. Veerakumar ${ }^{[7]}$ said that kapok/polypropylene fiber composites can be used as the sound absorbing material. Kapok fiber can also be mixed with thermoplastic cassava starch (TPCS) to reduce water uptake in TPCS / kapok composite and increase the stress on the maximum force and modulus young ${ }^{[8]}$.

Based on the background above, the researcher has the idea of doing physical testing and chemical resistance of kapok fiber both before and after soaking in order to obtain data on kapok content specifically and obtain physical properties data, analyze changes in properties from hydrophobic to hydrophilic and increase hydrophilic properties, analyze types solvent to increase absorbency of kapok fiber to water absorption. This research is important to be carried out considering the number of kapok trees which are very abundant in Gorontalo Province and their utilization is not maximized.

This study uses solvent $\mathrm{HCl}, \mathrm{NaOH}, \mathrm{NaClO}, \mathrm{NaClO}-\mathrm{NaOH}-\mathrm{NaClO}$, and $\mathrm{NaClO}_{2}-\mathrm{NaOH}-$ $\mathrm{NaClO}_{2}$ to remove lignin, pectin, hemicellulose, natural oil, and kapok wax so that changes occur from hydrophobic to hydrophilic. Researchers believe the use of a combination of solvents can change the hydrophobic nature to become hydrophilic for the better. 


\section{Materials and Methods}

\subsection{Materials}

Kapok fiber derived from Gorontalo province, Indonesia. Hydrochloric acid (37\%) solution, Sodium Hydroxide solids, Sodium hypochlorite (\%) solution and Sodium chlorite solution (\%) are obtained from PT. Sumber Utama Kimiamurni, Surabaya City, Indonesia.

\subsection{Preparation of Kapok Fiber}

Acid modification of Kapok Fiber with $\mathrm{HCl}$

Kapok fiber (4 grams) was put into $400 \mathrm{~mL} \mathrm{HCl}$ solution $(1 \mathrm{M}$ ) for 2 hours at room temperature. Then washed with distilled water to $\mathrm{pH}=7$ and dried for 24 hours at $40^{\circ} \mathrm{C}$. Preparation of natural materials be done in Metallurgy Laboratory.

\section{Alkali modification of Kapok Fiber with $\mathrm{NaOH}$}

Kapok fiber (4 grams) was put into $400 \mathrm{~mL}$ of $2 \mathrm{wt} \% \mathrm{NaOH}$ solution for 1 hour at $70^{\circ} \mathrm{C}$. After that, it was removed and washed with the glacial acetic acid solution $(100 \%)$ to $\mathrm{pH} 7$. Then proceed with washing using distilled water and dried for 24 hours at $40^{\circ} \mathrm{C}$.

\subsection{Oxidation modification of Kapok fiber with $\mathrm{NaClO}$}

Oxidation uses $\mathrm{NaClO}$ solution

Kapok fiber (4 grams) was soaked in $200 \mathrm{~mL}$ of $\mathrm{NaClO}(0.5 \mathrm{~N})$ and $2 \mathrm{~mL}$ glacial acetic acid solutions $(100 \%)$ for 1 hour, $80^{\circ} \mathrm{C}$. Then removed and washed with distilled water to $\mathrm{pH} 7$ and dried for 24 hours at $40^{\circ} \mathrm{C}$.

Oxidation uses $\mathrm{NaClO}-\mathrm{NaOH}-\mathrm{NaClO}$ solution

Kapok fiber (4 grams) was soaked in $200 \mathrm{~mL}$ of $\mathrm{NaClO}$ solution $(0.5 \mathrm{~N})$ and $2 \mathrm{~mL}$ glacial acetic acid $(100 \%)$ for 1 hour, $70^{\circ} \mathrm{C}$, then removed and suspended with $200 \mathrm{~mL} \mathrm{H}_{2} \mathrm{O}$ and $1.5 \mathrm{~mL}$ glacial acetic acid with the addition of 7.5 grams of $\mathrm{NaOH}$. Then stirring 10 minutes at room temperature. Then wash with aquadest to $\mathrm{pH} 7$, put in $100 \mathrm{~mL}$ of $\mathrm{NaClO}$ solution $(0.5 \mathrm{~N})$ for 10 minutes at $70^{\circ} \mathrm{C}$, washed with acetone, dried for 24 hours, $40^{\circ} \mathrm{C}$.

\subsection{Oxidation modification of kapok fiber with $\mathrm{NaClO}_{2}$}

A total of 4 grams of kapok fiber was put into $200 \mathrm{~mL}$ of $\mathrm{NaClO}_{2}$ solution $(0.5 \mathrm{~N})$ containing 2 $\mathrm{mL}$ of glacial acetic acid solution $(100 \%)$ for 1 hour at $70^{\circ} \mathrm{C}$. Then it was suspended with $200 \mathrm{~mL}$ of aquadest containing $1.5 \mathrm{~mL}$ of glacial acetic acid solution and 7.5 grams of $\mathrm{NaOH}$. Then stirred for 10 minutes at room temperature, removed and washed with distilled water to $\mathrm{pH} 7$. Then proceed with soaking in $100 \mathrm{~mL}$ of $\mathrm{NaClO}_{2}$ solution $(0.5 \mathrm{~N})$ for 10 minutes at $70^{\circ} \mathrm{C}$. After that it was washed with acetone, dried for 24 hours at $40^{\circ} \mathrm{C}$.

\subsection{Characterizations}

Fourier transforms infrared spectroscopy 
Fourier transforms infrared (FTIR) spectra were reported using scientific Thermo Nicolet iS10 at room temperature. The sample spectrum was measured at $500-4000 \mathrm{~cm}^{-1}$ wavelength. Material testing was carried out at the Material Characterization Laboratory, Department of Materials and Metallurgical Engineering, ITS, Indonesia.

\section{Scanning electron microscopy}

Scanning electron microscopy (SEM) is used to observe the microstructure and shape of the kapok fibers before and after treatment. SEM testing is done by coating the sample with $\mathrm{Au} / \mathrm{Pd}$ and analyzed using INSPECTTM S50 SEM microscope apparatus. SEM testing was carried out at the Material Characterization Laboratory, ITS, Indonesia.

\subsection{Determination of Porosity and Cellulose}

Porosity and cellulose content in kapok fibers can be determined using bulk density, absolute density, and cellulose density ${ }^{[9]}$. Bulk density $\left(\rho_{b}\right)$ can be calculated using equation 1 .

$\rho_{b}=\frac{\rho_{s} W_{f a}}{W_{f a}-W_{f s}}$

Where $\rho_{s}$ is toluene solvent density, $867 \mathrm{~kg} / \mathrm{m}^{3} . W_{f a}$ is initial weight of fiber $(\mathrm{kg})$ and $W_{f s}$ is the weight of the immersed fiber. All measurements were determined at a temperature of $19^{\circ} \mathrm{C}$ and the weight was measured at the nearest $0,001 \mathrm{~g}$.

\subsection{Water Absorption}

Water absorption in kapok fiber is determined by referring to the ASTM C209 and ASTM D5229 $M$ testing standards based on equation 2. Water Absorption Tests were carried out at the Metallurgy Laboratory, Gorontalo State University, Indonesia. The specimens were immersed in water for $1,2,3,4,5,6,7,8,9,10,11,12,13,14,15,16,17,18,19,20,21,22,23$, dan $24 \mathrm{~h}$, respectively. After immersion, the surfaces of the specimens were dried with tissue paper and weighed to measure their wet weigth. Formula of the water absorption can be seen in equation 2 .

$\%$ Moisture sorption $=\left(\frac{W_{i}-W_{b}}{W_{b}}\right) \times 100$

Soaking is done for 24 hours in relative humidity at room temperature. Where $W_{b}$ is the initial weight, $W_{i}$ is heavy after being immersed in water. Tests are carried out on all kapok fibers both un-treatment and those that have been treated.

\section{Results and Discussions}

\subsection{Modification of Kapok Fibers}

Kapok fiber was modified through a process of soaking in various solvents, included $\mathrm{HCl}, \mathrm{NaOH}$, $\mathrm{NaClO}, \mathrm{NaClO}-\mathrm{NaOH}-\mathrm{NaClO}$, and $\mathrm{NaClO}_{2}-\mathrm{NaOH}-\mathrm{NaClO}_{2}$ solution. Immersion in each solution through different stages. Immersion in $\mathrm{HCl}(1 \mathrm{M})$ solution did not show significant changes. This is proven by the results of $\mathrm{HCl}$-treated kapok fiber FTIR which is similar to untreated kapok. Based 
on Fig 1, the intensity of kapok fiber absorption in $\mathrm{HCl}$ solution at a peak of $1732.16 \mathrm{~cm}^{-1}$ in the form of $\mathrm{C}=\mathrm{O}$ group did not change. Acidic solutions in $\mathrm{HCl}$ solution cannot break the $\pi$ bond in the $\mathrm{C}=\mathrm{O}$ group which indicates the presence of lignin, pectin, and kapok wax. As a result, after soaking the kapok still remains hydrophobic. This is evident in the data in Table 2. Water absorption in HCl-treated kapok is only $55.28 \%$, while water absorption in untreated kapok is around $46 \%$. Water absorption in $\mathrm{HCl}$-treated is low compared to other solvents, both alkaline and oxidation solvents. The amount of water absorption on the untreated kapok and HCl-treated levels is caused by water molecules trapped in the hollow part of the kapok fiber. HCl-treated can only eliminate hemicellulose, especially xylose ${ }^{[10,11]}$.

Immersion of kapok fiber in alkaline solution in the form of $\mathrm{NaOH}$ solution (2\%) causes changes in kapok from hydrophobic to hydrophilic properties. This can be seen from the loss of peak in the area of $1732.16 \mathrm{~cm}^{-1}$ which indicates that the $\pi$ bond has been broken on the $\mathrm{C}=\mathrm{O}$ function group. The change in nature from hydrophobic to hydrophilic is also evidenced by a large amount of sorption from the solution. The same thing also happens when kapok fibers are soaked in a solution of $\mathrm{NaClO}, \mathrm{NaClO}-\mathrm{NaOH}-\mathrm{NaClO}$, and $\mathrm{NaClO}_{2}-\mathrm{NaOH}-\mathrm{NaClO}_{2}$.

\subsection{FTIR Analysis of Kapok Fiber}

The different types of solutions used as kapok fiber solvents cause intensity differences in peaks as shown in Fig. 1 At peak $3342.32 \mathrm{~cm}^{-1}$ shows the $-\mathrm{OH}$ group stretching vibration ${ }^{[12]}$ and indicates the presence of cellulose ${ }^{[13]}$. There is an increase in the intensity of O-H stretching because immersion in acids, alkalis, and oxidation can increase the number of free hydroxyl groups in cellulose units. Peak $2916.26 \mathrm{~cm}^{-1}$ indicates asymmetric and symmetric aliphatic $\mathrm{CH}_{2}$ and $\mathrm{CH}_{3}$ stretching ${ }^{[4,14]}$. This generally identifies the existence of surface wax ${ }^{[1]}$.

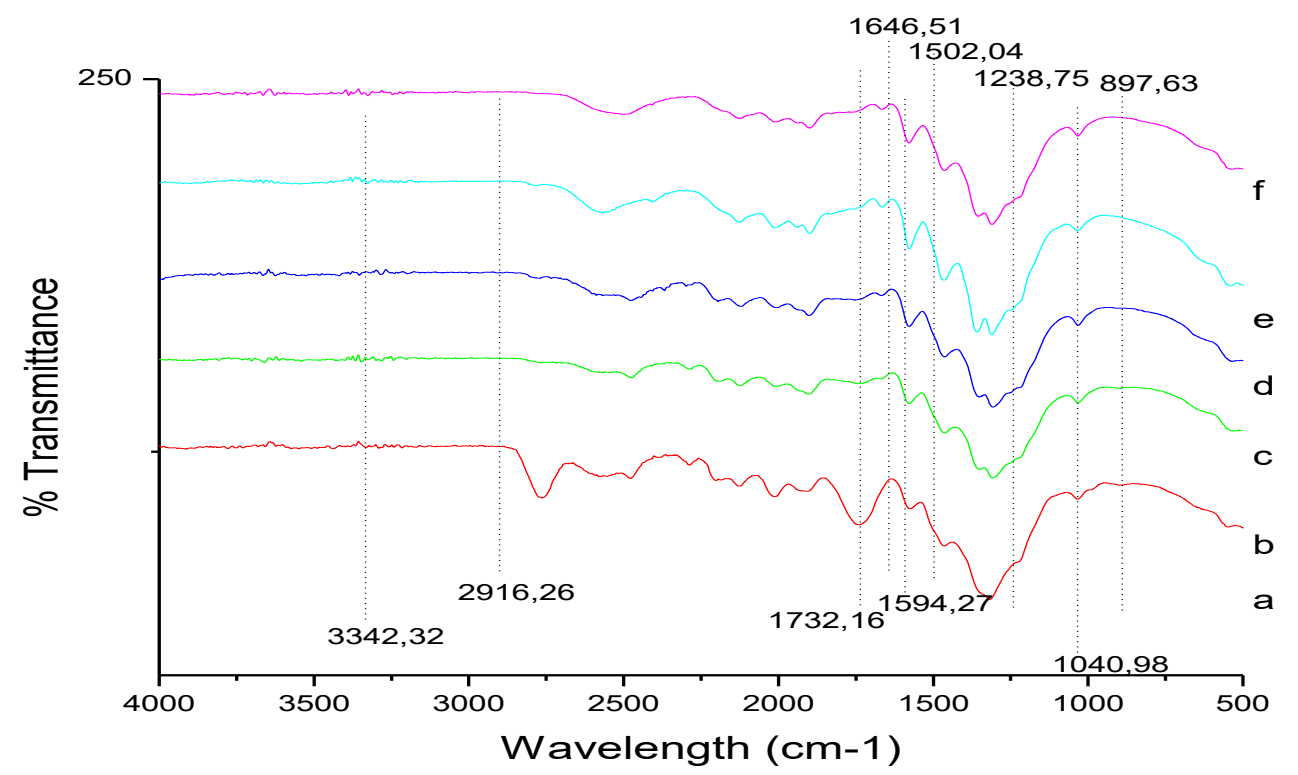

Figure 1: FTIR Spectra of (a) untreated kapok, (b) HCl-treated kapok, (c) $\mathrm{NaOH}$-treated kapok, (d) NaClO-treated kapok, (e) $\mathrm{NaClO}-\mathrm{NaOH}-\mathrm{NaClO}$-treated kapok, and (f) $\mathrm{NaClO}_{2}-\mathrm{NaOH}$ $\mathrm{NaClO}_{2}$-treated kapok 
The decrease in intensity at peak $2916.26 \mathrm{~cm}^{-1}$ appears in $\mathrm{NaOH}$-treated and $\mathrm{NaClO}_{2}-\mathrm{NaOH}_{-}$ $\mathrm{NaClO}_{2}$-treated. This is due to the effect of alkali on $\mathrm{NaOH}$ solution and oxidation in $\mathrm{NaClO}_{2}$ solution. Peak $1732.16 \mathrm{~cm}^{-1}$ is $\mathrm{C}=\mathrm{O}$ stretching vibration group. This peak shows the presence of ketones, carboxylic groups, and esters in lignin and acetyl ester groups in xylan ${ }^{[15,16]}$. The carbonyl group $\mathrm{C}=\mathrm{O}$ in ester group also indicates that it is kapok wax ${ }^{[4]}$. There was a decrease in intensity at peak $1732.16 \mathrm{~cm}^{-1}$ and indicating a decrease in the amount of lignin and hemicellulose due to the breakdown of the carbonyl $\mathrm{C}=\mathrm{O}$ by the effect of the alkaline solution and oxidation solution. Acid (in this case $\mathrm{HCl}$ ) is unable to break the carbonyl group. Peak $1646.51 \mathrm{~cm}^{-1}$ also shows group $\mathrm{C}=\mathrm{O}$ stretching ${ }^{[14]}$. This peak also indicates the presence of hemicellulose and in the presence of a peak at $897 \mathrm{~cm}^{-1}$ indicates the presence of $\beta$-linked hemicellulose ${ }^{[2]}$.

The peak of $1594.27 \mathrm{~cm}^{-1}$ shows the presence of the backbone ring benzene together with a peak of $1502.04 \mathrm{~cm}^{-1}[13]$. This peak has decreased in $\mathrm{NaClO}-\mathrm{NaOH}-\mathrm{NaClO}$-treated and $\mathrm{NaClO}_{2}-\mathrm{NaOH}-$ $\mathrm{NaClO}_{2}$ due to phenolic compounds which are part of lignin damaged ${ }^{[17]}$ and turned into hydroxyl groups which increase the intensity at peak $3342.32 \mathrm{~cm}^{-1}$. Peak $1238.75 \mathrm{~cm}^{-1}$ is a C-O bending vibration group. This peak shows the presence of lignin and hemicellulose. Peak $1040.98 \mathrm{~cm}^{-1}$ indicates carbohydrates and polysaccharides which signify cellulose clusters ${ }^{[4]}$. This peak does not experience significant changes in intensity indicating no changes that occur specifically in cellulose.

\subsection{Physical Propeties of Kapok Fiber}

Porosity and cellulose of kapok fiber

One of the physics tests used in this study is to test the porosity and cellulose levels of kapok fibers. The results obtained after testing can be seen in Table 1 about porosity and cellulose of kapok fiber. Based on Table 1, we can see the values of porosity and cellulose from kapok fibers.

Table 1: Porosity and cellulose content of kapok fiber

\begin{tabular}{|c|c|c|c|c|c|c|c|}
\hline $\begin{array}{c}N \\
o\end{array}$ & $\begin{array}{c}\text { Fiber Type of } \\
\text { Kapok }\end{array}$ & $\begin{array}{c}\text { Diamete } \\
r\end{array}$ & $\begin{array}{c}\text { Porosit } \\
y\end{array}$ & $\begin{array}{c}\text { Non- } \\
\text { cellulose }\end{array}$ & $P+X$ & {$[(P+X)-Y]$} & $\begin{array}{c}\text { Cellulose } \\
\text { content }\end{array}$ \\
\hline & & $(\mu \mathrm{m})$ & $\mathbf{P}(\%)$ & $+\operatorname{air} Y(\%)$ & $Y^{\prime}(\%)$ & Tair (\%) & $\mathbf{Z}(\%)$ \\
\hline 1 & Untreated & 17.62 & 40.79 & 41.66 & 42.27 & 0.60 & 57.13 \\
\hline 3 & HCl-treated & 16.58 & 26.40 & 27.49 & 27.88 & 0.39 & 71.73 \\
\hline 2 & $\mathrm{NaOH}$-treated & 14.21 & 11.69 & 12.99 & 13.17 & 0.17 & 86.66 \\
\hline 4 & $\begin{array}{l}\text { NaClO- } \\
\text { Treated }\end{array}$ & 15.76 & 11.99 & 13.30 & 13.48 & 0.18 & 86.34 \\
\hline 5 & $\begin{array}{l}\text { NaClO-NaOH- } \\
\text { NaClO- } \\
\text { Treated } \\
\end{array}$ & 12.31 & 5.73 & 7.12 & 7.21 & 0.08 & 92.71 \\
\hline 6 & $\begin{array}{l}\text { NaClO2- } \\
\mathrm{NaOH}- \\
\text { NaClO2- } \\
\text { Treated }\end{array}$ & 11.12 & 4.75 & 6.16 & 6.23 & 0.07 & 93.69 \\
\hline
\end{tabular}

Of the six types of kapok fiber, untreated kapok has the highest porosity value of $40.79 \%$ and the lowest cellulose content is $57.13 \%$. The $\mathrm{NaClO}_{2}-\mathrm{NaOH}-\mathrm{NaClO}_{2}$-Treated has the lowest porosity content $(4.75 \%)$ and the highest cellulose content of $93.69 \%$. The greater the value of porosity, the 
lower the cellulose content. As previously explained, the effect of alkalization and oxidation on kapok fibers causes loss of lignin, pectin, hemicellulose, wax and natural oils which protect the fiber surface ${ }^{[3,10]}$ so that only cellulose remain.

\subsection{Water Absorption}

In addition to testing the porosity and cellulose content, water absorption test was also carried out to measure the amount of water absorbed by kapok both untreated and treated kapok. Water absorption is also one of the determinants of changes in the nature of kapok from hydrophobic to be hydrophilic.

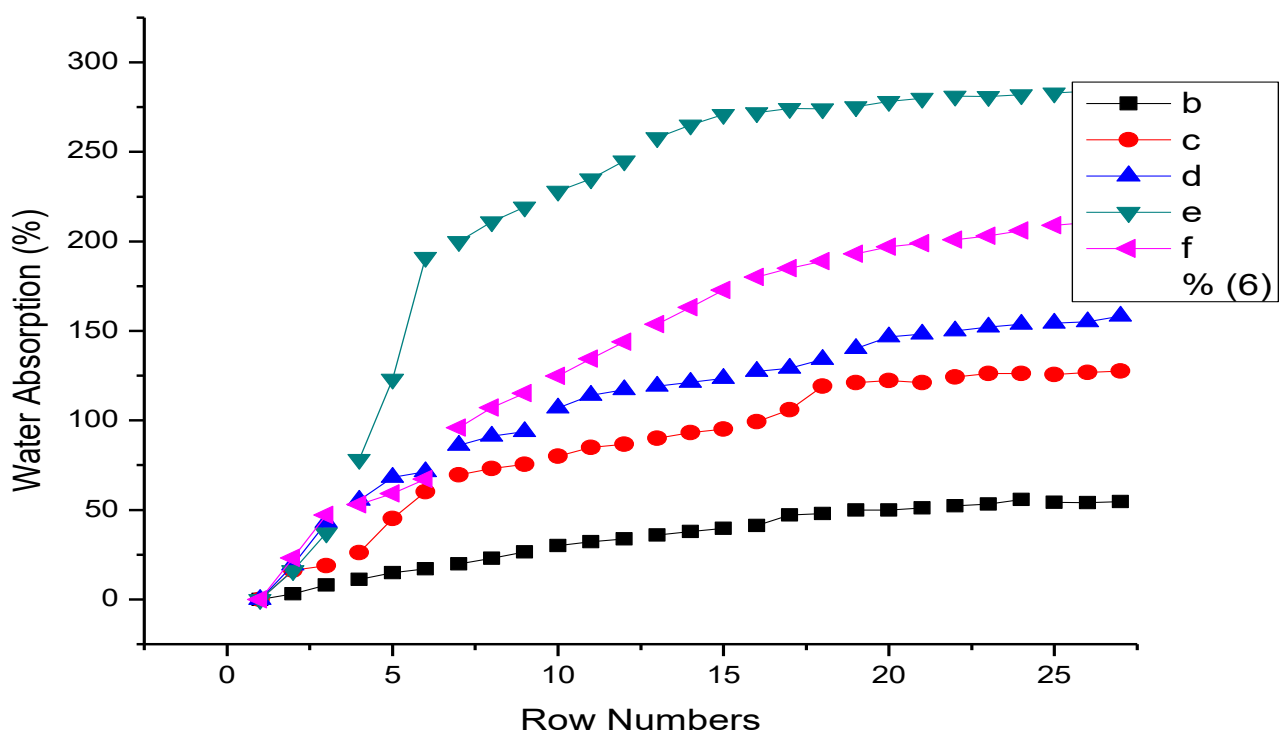

Figure 2: Water absorption of (a) untreated kapok, (b) HCl-treated, (c) NaOH-treated, (d)NaClOtreated, (e) NaClO-NaOH-NaClO-treated, and (f) $\mathrm{NaClO}_{2}-\mathrm{NaOH}-\mathrm{NaClO}_{2}$-treated

Based on Figure 2 about water absorption of natural fiber can be seen the percentage of water absorption from fiber type of kapok. From the six types of kapok, untreated moisture sorption has the smallest moisture sorption value of about $45.29 \%$, while $\mathrm{NaClO}-\mathrm{NaOH}-\mathrm{NaClO}$-treated kapok has the highest moisture sorption percentage of around $285.29 \%$. The difference in the percentage of moisture sorption from each type of kapok is due to untreated-kapok having hydrophobic properties because of the surface wax and natural oil in kapok which in theory kapok fiber cannot absorb water. The amount of percentage of water absorption on untreated kapok is due to the water being trapped between the fibers. Likewise, with HCl-treated acid, although it has the ability to remove kapok wax, $\mathrm{HCl}$-treated cannot remove lignin and pectin from kapok and is only capable of removing xylose hemicellulose ${ }^{[10,11]}$.

$\mathrm{NaClO}-\mathrm{NaOH}-\mathrm{NaClO}$-treated has the largest water absorption percentage value. This is because there are more than one immersion stage, which begins with $\mathrm{NaClO}$-treated oxidation, then proceed with the $\mathrm{NaOH}$ alkalization process, and after that it is treated again with oxidation of 
$\mathrm{NaClO}$, so that non-cellulose compounds (hemicellulose, lignin, and pectin) are eliminated significantly and cause changes in the nature of kapok from hydrophobic to be hydrophilic. When compared with $\mathrm{NaClO}_{2}-\mathrm{NaOH}-\mathrm{NaClO}_{2}$-treated from the results of the study, $\mathrm{NaClO}$ solution is more effective in terms of the ability to absorb water even though it has a cellulose content lower than the $\mathrm{NaClO}_{2}$ solution. Both $\mathrm{NaClO}$ and $\mathrm{NaClO}_{2}$ are oxidation solutions.

\subsection{Scanning Electron Microscopy of Kapok Fiber}

Based on SEM analysis (Fig. 3), there is a significant difference between untreated kapok and treated kapok. Fig. 3. a and b are untreated. It can be seen the smooth and round hollow lumen shape of the kapok fiber. When treated well using a solution of $\mathrm{NaClO}-\mathrm{NaOH}-\mathrm{NaClO}$ (Fig 4. c and d) and a solution of $\mathrm{NaClO}_{2}-\mathrm{NaOH}-\mathrm{NaClO}_{2}$ (Fig 4. e and f) there are a change in the shape of the kapok fiber. The fibers become wrinkled, rough, non-glossy, and there were particulates on the surface of the fiber after soaking. Particulate attached to the surface of the fiber is caused by stretching the pores of the fiber so that it can suck particles in the water (see red circle image $3 \mathrm{e}$ and f). The loss of non-cellulose compounds causes kapok to change the nature of hydrophobicity to be hydrophilic. The loss of lignin, pectin, wax and natural oil that covers the surface of the fiber is also able to improve the surface and mechanical properties for polymer applications ${ }^{[3,18]}$.

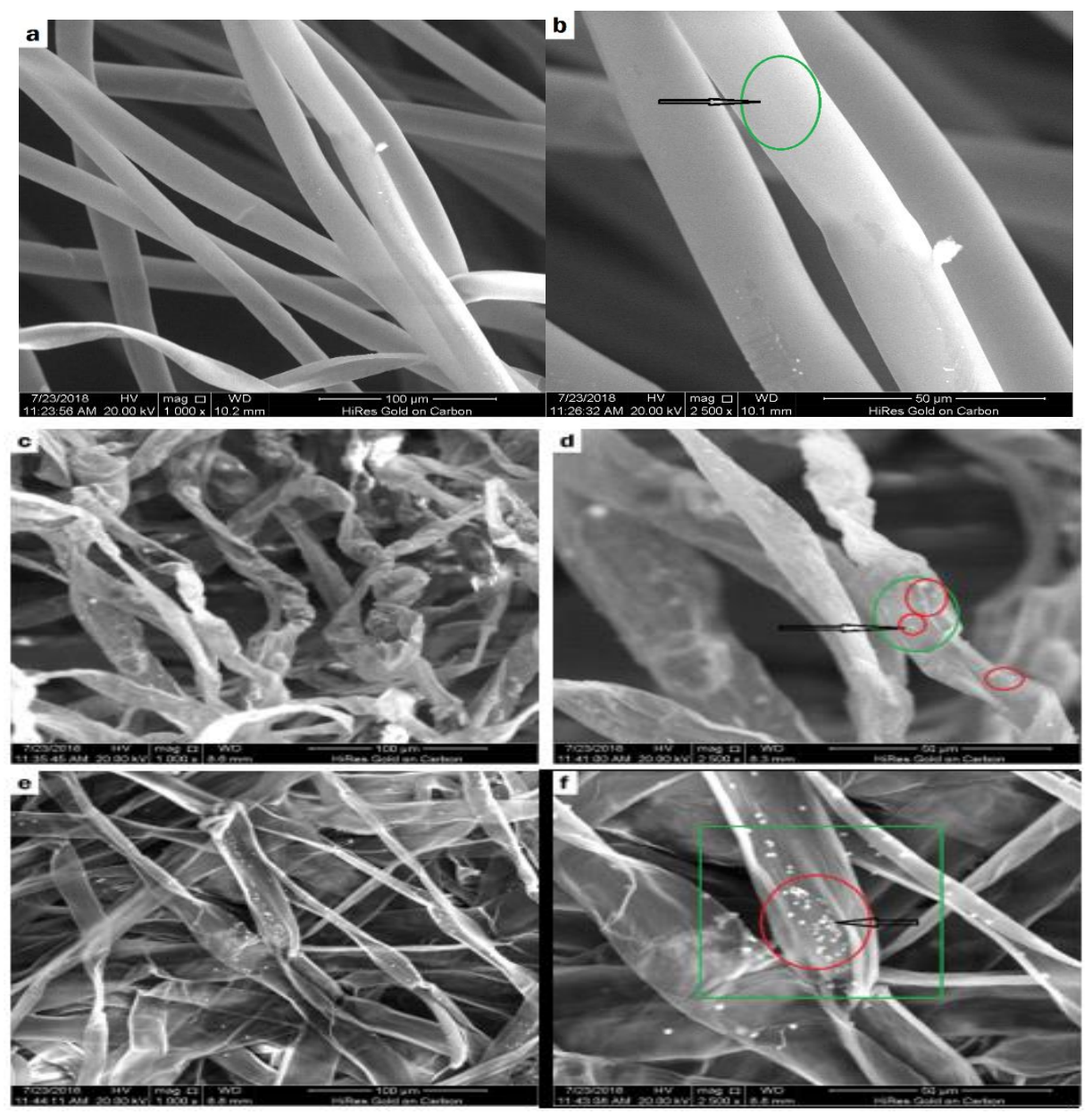

Figure 3: SEM Micrograph of (a and b) untreated kapok, (c and d) $\mathrm{NaClO}-\mathrm{NaOH}-\mathrm{NaClO}$ treated, and (e and f) $\mathrm{NaClO}_{2}-\mathrm{NaOH}-\mathrm{NaClO}_{2}$-treated kapok 


\section{Conclusions and Recommendations}

Physical properties and chemical stability of the kapok were investigated. The results of this study indicate that untreated kapok has hydrophobic properties. Treatment with various solvents causes changes in properties. HCl-treated does not significantly influence changes in kapok. This is because $\mathrm{HCl}$ is only able to reduce hemicellulose levels, especially xylose in kapok so that the kapok still remains hydrophobic. Treatment using an alkaline solution $(\mathrm{NaOH})$ causes a change in the nature of kapok from hydrophobic to hydrophilic. This is because the $\mathrm{NaOH}$ base can damage the ester group in the kapok fibers so that both lignin, pectin, hemicellulose and kapok wax can be removed. $\mathrm{NaOH}$-treated is better than $\mathrm{HCl}$-treated. The use of oxidation solution has a better effect than acidic or basic solutions. The collaboration of alkaline and oxidation solutions such as $\mathrm{NaClO}-$ $\mathrm{NaOH}-\mathrm{NaClO}$-treated and $\mathrm{NaClO}_{2}-\mathrm{NaOH}-\mathrm{NaClO}_{2}$-treated has a greater influence in removing non-cellulose compounds and is also able to increase amorphous cellulose which has the effect of increasing cellulose content, increased water absorption capacity and the nature of chemical stability is getting better.

\section{Acknowledgements}

The author provides a great appreciation to the Ministry of Research and Technology of Indonesia as a contributor to the research fund.

\section{References}

[1] Wang J, Zheng Y, Wang A (2012) Effect of Kapok Fiber Treated with Various Solvent on Oil Absorbency. J Industrial Crops and Prod 40:178-184. http://doi.org/10.1016/j.indcrop. 2012.03.002

[2] Duan C, Zhao N, Yu X, Zhang X, Xu J (2013) Chemically Modified Kapok Fiber for Fast Adsorption of $\mathrm{Pb} 2+, \mathrm{Cd} 2+, \mathrm{Cu} 2+$ From Aqueous Solution. Cellulose 20:849-860. http:// doi.org/10.1007/s10570-013-9875-9

[3] Wahi R, Chuah LA, Choong TSY, Ngaini Z, Nourouzi MM (2013) Oil Removal From Aqueous State by Natural Fibrous Sorbent: An Overview. Sep Purif Tech 113:51-63. https://doi.org/10.1016/j.seppur.2013.04.015

[4] Abdullah MA, Rahmah AU, Man Z (2010) Physicochemical and Sorption Characteristics of Malaysian Ceiba pentandra (L.) Gaertn. as a Natural Oil Sorbent. J Hazard Mater 177:683-691. https://doi.org/10.1016/ j.jhazmat.2009.12.085

[5] Hori K, Flavier ME, Kuga S, Lam TBT, Liyama K (2000) Excellent Oil Absorbent Kapok [Ceiba pentandra (L.) Gaertn.] Fiber: Fiber Structure, Chemical Characteristics, and Application. J Wood Sci 46:401-404. http://doi.org/10.1007/BF00776404

[6] Wang R, Shin CH, Park S, Park JS, Kim D, Cui L, Ryu M (2014) Removal of Lead (II) From Aqueous Stream by Chemically Enhanced Kapok Fiber Adsorption. J Environ Earth Sci 72:52215227. https://doi.org/10.1007/s12665-014-3804-6

[7] Veerakumar A, Selvakumar N (2012) A Preliminary Investigation on Kapok/ Polypropylene Nonwoven Composite for Sound Absorption. Indian J Fibre Text 37:385-388.

[8] Prachayawarakorn J, Chaiwatyothin S, Mueangta S, Hanchana A (2013) Effect of Jute and Kapok Fibers on Properties of Thermoplastics Cassava Startch Composites. J Mat \& Design 47:309-315. https://doi.org/10.1016/j.matdes.2012.12.012

[9] Mwaikambo LY, Ansell MP (2001) The Determination of Porosity and Cellulose Content of Plant Fibers by Density Methods. J Mater Sci Letters 20:2095-2096. http//doi.org/10.1023/ A:1013703809-964 
[10] Zheng Y, Wang J, Zhe Y, Wang A (2014) Research and Application of Kapok Fiber as an Absorbing Material: A Mini Review. J Environ Sci 27:21-32. https://doi.org/10.1016/j.jes. 2014.09.

[11] Tye YY, Lee KT, Abdullah WNW, Leh CP (2013) Potential of Ceiba pentandra (L.) Gaertn. (Kapok) Fiber as a Resource for Second Generation Bioethanol: Parametric Optimization and Comparative Study of Various Pretreatments Perior Enzymatic Saccharification for Sugar Production. Bioresour Technol 140:10-14. https://doi.org/10.1016/j.biortech. 2013.04.069

[12] Wang J, Geng G, Liu X, Han F, Xu J (2016) Magnetically Superhydrophobic Kapok Fiber for Selective Sorption and Continuous Separation of Oil from Water. J Chem Eng Res \& Des 115:122130. https://doi.org/10.1016/j.cherd.2016.09.032

[13] Liu J, Wang F (2011) Influence of Mercerization on Micro-structure and Properties of Kapok Blended Yarns with Different Blending Ratios. J Eng Fibers \& Fabr. 6:63-68

[14] Pakaya F, Ardhyananta H, Wicaksono ST (2017) Mechanical Properties and Thermal Stability of Epoxy/ RTV Silicone Rubber. J Tech and Sci 28:7-14. http://dx.doi.org/10. 12962/ j20882033.v28i1.2216

[15] Wang F, Zheng Y, Zhu Y, Wang A (2016) Oriented Functionalization of Natural Hollow Kapok Fiber for Highly Efficient Removal of Toxic Hg (II) from Aqueous Solution. J Front Environ Sci 4:1-12. https://doi.org/10.3389/fenvs.2016.00004

[16] Barlianti V, Dahnum D, Hendarsyah H, Abimayu H (2015) Effect of Alkaline Pretreatment on Properties of Lignocellulosic Oil Palm Waste. J Procedia Chem 16:195-201. https://doi.org/10.1016/j.proche.2015.12.036

[17] Chung BY, Cho JY, Lee MH, Wi SG, Kim JH, Kim JS, Kang PH, Nho YC (2008) Adsorption of Heavy Metal Ions onto Chemically Oxidized Ceiba Pentandra (L.) Gaertn. (Kapok) Fibers. J Appl Biol Chem 51:28-35. http://doi.org/10.3839/jabc.2008.006

[18] Reddy GV, Naidu SV, Rani TS (2009) A Study on Hardness and Flexural Properties of Kapok/Sisal Composites. J Reinf Plast Comp 28:2035-2044. https://doi.org/10.1177/ 0731684408091682

*Corresponding author.

E-mail address: fahriadi.pakaya@ yahoo.co.id 